http://www.jfas.info

\title{
SIMULATION OF U-SHAPED PLASTIC OPTICAL FIBER ETHANOL SENSOR
}

\author{
H. Saad ${ }^{1}$, M. K. A. Rahman ${ }^{2,}$, M. H. M.Yusoff ${ }^{2}$, N. S. M. Kassim² and I. Yassin ${ }^{1}$ \\ ${ }^{1}$ Faculty of Electrical Engineering, Universiti Teknologi MARA, 40450 Shah Alam, Selangor, \\ Malaysia \\ ${ }^{2}$ Faculty of Applied Sciences, Universiti Teknologi MARA, 40450 Shah Alam, Selangor, \\ Malaysia
}

Published online: 05 October 2017

\begin{abstract}
The prediction of optical loss in different bending diameter of U-shaped POF sensor toward variation of ethanol's refractive indices was investigated using ray-tracing method perform by Zemax software. It can provide information on how the propagation ray is perturbed by different bending diameter of U-shaped POF. There are five designs of POF models were pre-drawn with different bending diameter; $2.0 \mathrm{~cm}, 2.5 \mathrm{~cm}, 3.0 \mathrm{~cm} 3.5 \mathrm{~cm}$ and $4.0 \mathrm{~cm}$. From the results, U-shaped with $2.5 \mathrm{~cm}$ bending diameter has shown the most sensitive bending diameter as compared to the rest. Either with the presence of cladding layer or not the sensitivity detected was $0.014 \times 10^{-4}$ Watts $/ \mathrm{Vol} \%$.
\end{abstract}

Keywords: ray-tracing; Zemax software; U-shaped POF sensor; ethanol sensor.

Author Correspondence, e-mail: drkamil@salam.uitm.edu.my

doi: $\underline{\text { http://dx.doi.org/10.4314/jfas.v9i4s.23 }}$

\section{INTRODUCTION}

Experimental work on ethanol sensing based POF was reported in [1-4]. Tapering and bending fiber had demonstrated better performance as compared to the straight fiber. U-shaped is the simplest form of bending. On the other hand, simulation work on fiber optic sensor also was reported in [5-9]. It plays an important role in predicting the response of the 
fiber optic sensor towards surrounding. However, to the best of our knowledge, there is no detail simulation work done in investigating the response of POF sensor toward variation of ethanol's refractive index. Finite-difference time-domain (FDTD), Finite Difference Beam Propagation Method (FD-BPM), Beam Propagation Method (BPM) and Ray-tracing method are the most commonly simulator used. Among all the simulators, ray-tracing method required less computer memory and suitable for high cross-sectional fiber like POF. This simulation work is helpful in giving the brief view about the POF sensor performance. It can shorten the time in designing and reduced the fabrication cost effectively. In this study, ray-tracing method by Zemax software demonstrates its potential ability to trace the ray propagation along the section of U-shaped multimode step-index POF for ethanol concentration sensing. It can provide information on how the propagation ray is perturbed by the different bending diameter of U-shaped POF. The optical loss caused by the bent section was analyzed as to find the most sensitive one.

\section{METHODOLOGY}

The overall research method involved in the simulation work can be shown in Fig. 1.

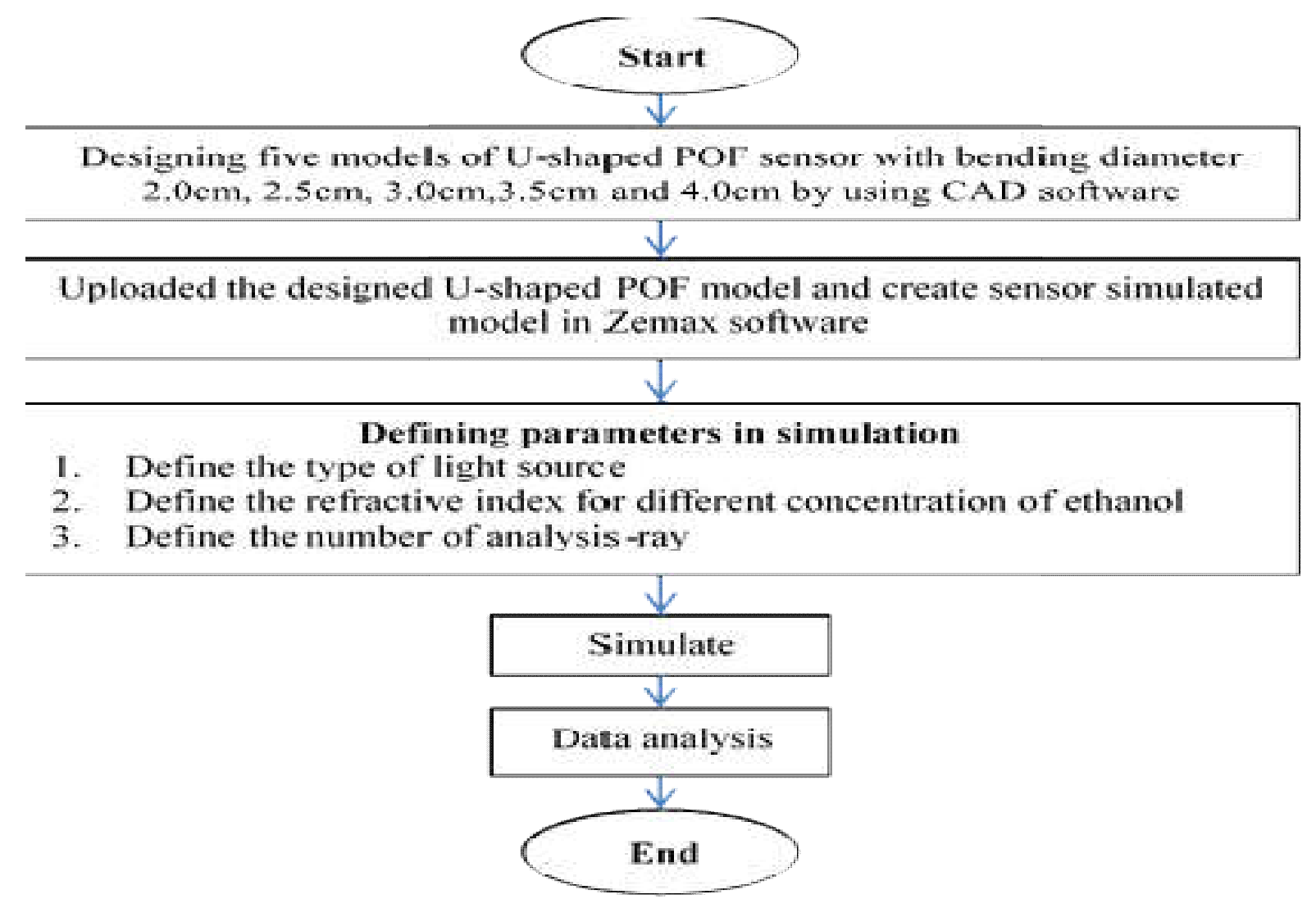

Fig.1. Research methodology

Each of the components in Fig. 1 will be explained in detail in the following subsections. 


\subsection{Designing U-Shaped POF Sensor with Different Bending Diameter}

The research work was started with designing several U-shaped POF model that have different bending diameter by using Computer Aided Design (CAD) software namely Solid Work. There are five designs of POF models were pre-drawn with different bending diameter. The bending diameter of the U-shaped POF was determined based on the curvature radius of the POF bending as in Fig. 2 [10].

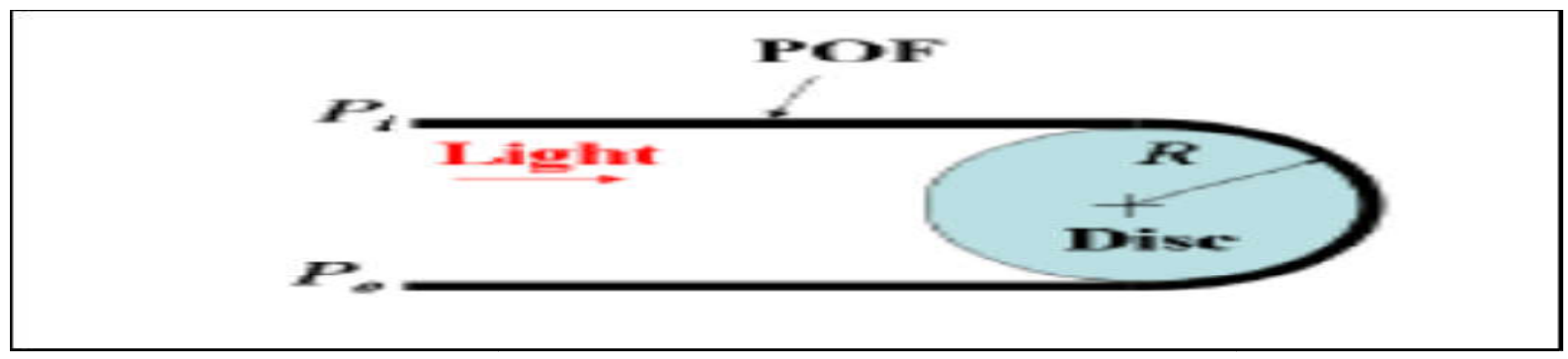

Fig.2. Illustration of curvature bent radius

The designed bending diameter was $2.0 \mathrm{~cm}, 2.5 \mathrm{~cm}, 3.0 \mathrm{~cm} 3.5 \mathrm{~cm}$ and $4.0 \mathrm{~cm}$. The illustration of the U-shaped POF designs can be shown in Fig. 3.

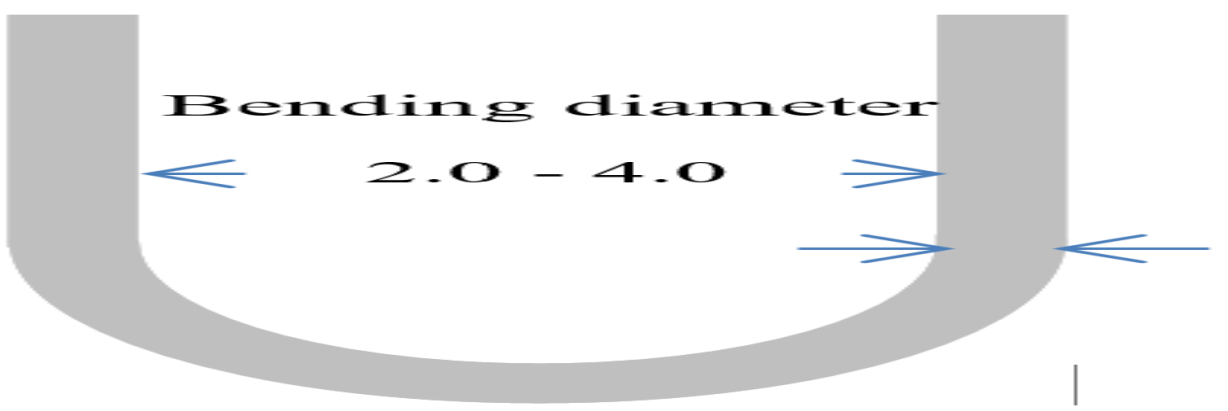

Fig.3. U-shaped with bending diameter varies from $2-4 \mathrm{~cm}$

These U-shaped designs have $980 \mu \mathrm{m}$ thickness which represents the core of POF without cladding.

\subsection{Designing the Simulated Model of POF Ethanol Sensor}

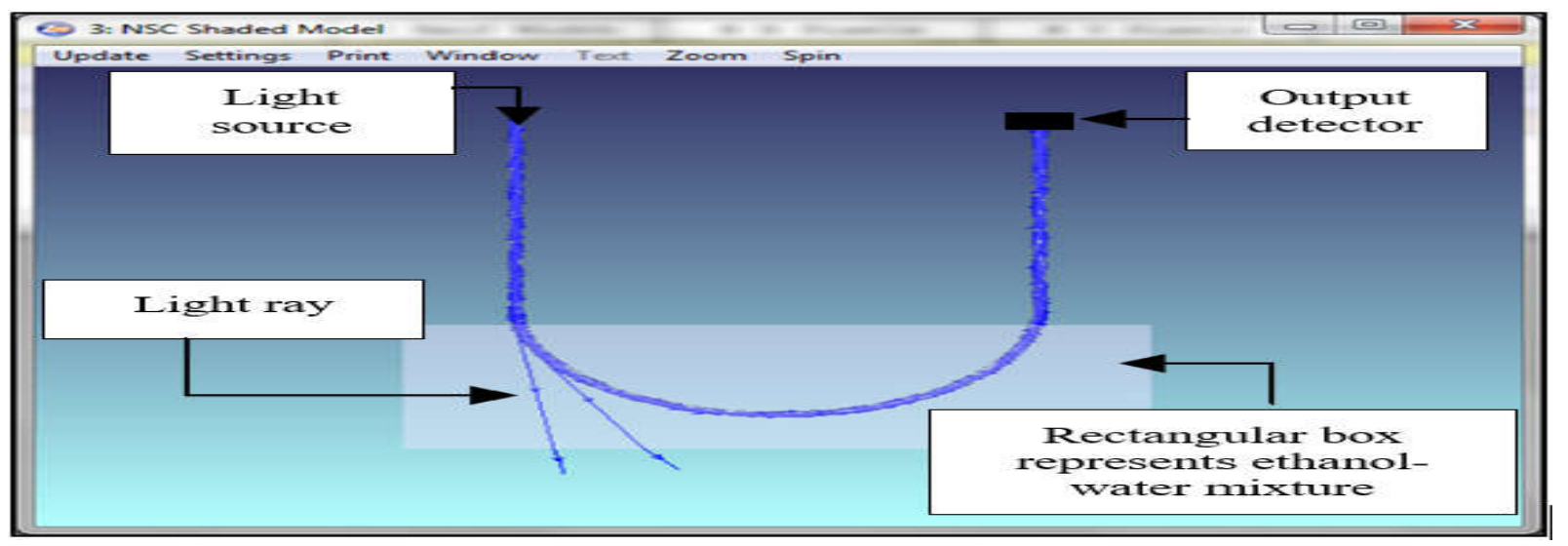

Fig.4. U-shaped POF ethanol sensor simulated model 
The designed U-shaped POF from the CAD software was uploaded into Zemax software and placed at defined orientation. The refractive index for POF core and cladding are defined as 1.492 and 1.42 respectively. The wavelength of the optical light source employed is $650 \mathrm{~nm}$ with an input power of $1.0 \mathrm{~mW}$. The ethanol-water mixture is designed to be in rectangular box. The dimension of the rectangular box was $20 \mathrm{~mm}$ x $20 \mathrm{~mm}$ x $50 \mathrm{~mm}$. The concentrations of the ethanol-water mixture are varied by changing their refractive index. The amount of output power arrived at the receiving end of the fiber will be detected by the detector called 'Detector Rectangle'. It is a flat detector in rectangular form. It has been defined to absorb all the energy that strikes its surface. Fig. 5 shows the image of light captured at the output detector. Some of the light may escaped from the fiber due to bending structure as shown in a Fig. 4. The surface area of the detector was set at a slightly larger size than the surface of the POF as to ensure it captures all the light rays emerging from the output fiber [11].

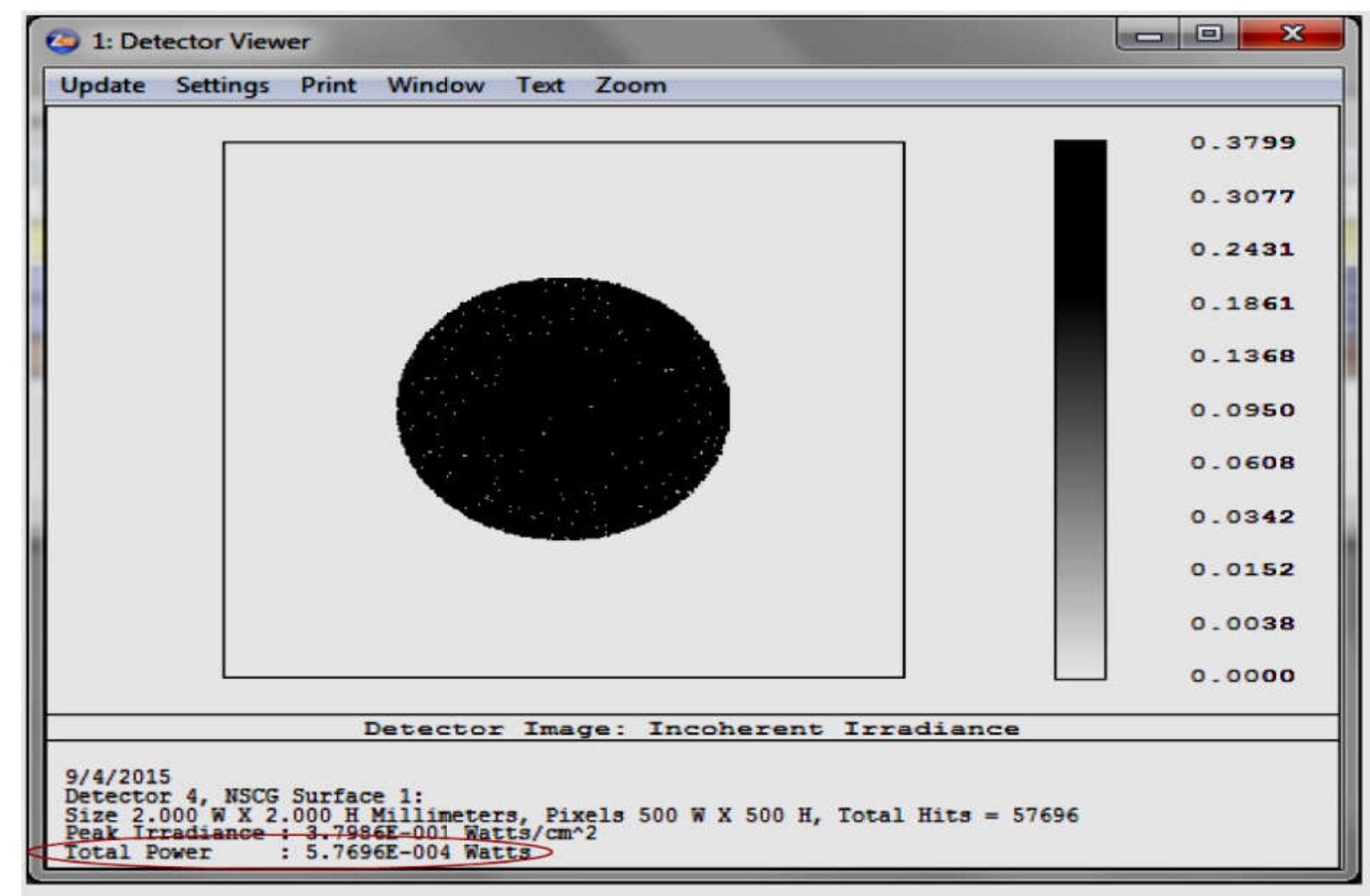

Fig.5. Image captured at output detector viewer

From the output detector viewer in Fig. 5, incoherent means the phase of the lights arrived at the detected are not in phase while the irradiance is the radiant flux (power) received by a surface per unit area [101]. Here, only value of total power is considered.

\subsection{Defining the Light Source}

In simulation work, the model of the light source used was Source diode. This light source was available in the Zemax light source library [11]. It has an intensity distribution given by: 
$I\left(\theta_{x}, \theta_{y}\right)=I_{o} e^{-2\left(\left(\frac{\theta_{x}}{\alpha_{x}}\right)^{2 G_{x}}+\left(\frac{\theta_{y}}{\alpha_{y}}\right)^{2 G_{y}}\right)}$

From Equation (1), $\alpha_{\mathrm{x}}$ and $\alpha_{\mathrm{y}}$ are the $\mathrm{XZ}$ and $\mathrm{YZ}$ divergence angle in degrees. Most laser diode manufacturers specify the divergence angles as the full width of the distribution between the half power points, $\theta_{\text {fwhm }} . G_{x}$ and $G_{y}$ are the "supergaussian" factor for the $X$ and $\mathrm{Y}$ direction. Both $\mathrm{G}_{\mathrm{x}}$ and $\mathrm{G}_{\mathrm{y}}$ can have the value in the range of 0.01 to 1 . Theoretically, $\mathrm{a}$ Gaussian distribution has $G_{x}$ or $G_{y}$ equal to 1.0. When considering only the light intensity, $I$ in the x-direction, then $\theta_{\mathrm{y}}$ become zero. For $\mathrm{G}_{\mathrm{x}}=1$, setting the left-hand side of the equation to $0.5 \mathrm{I}_{\mathrm{o}}$ and substituting $\theta_{\mathrm{x}}=0.5 \theta_{\text {fwhm. }}$. Then, $\alpha_{\mathrm{x}}$ will results as Equation (2) or (3).

$$
\alpha_{x}=\frac{\theta_{f w h m}}{\sqrt{2 \ln (2)}}
$$

or

$$
\alpha_{x}=(0.8493218) \theta_{f w h m}
$$

\subsection{Defining the Refractive Index for Different Concentration of Ethanol}

Fig. 6 shows the process of determining refractive index for different concentration of ethanol.

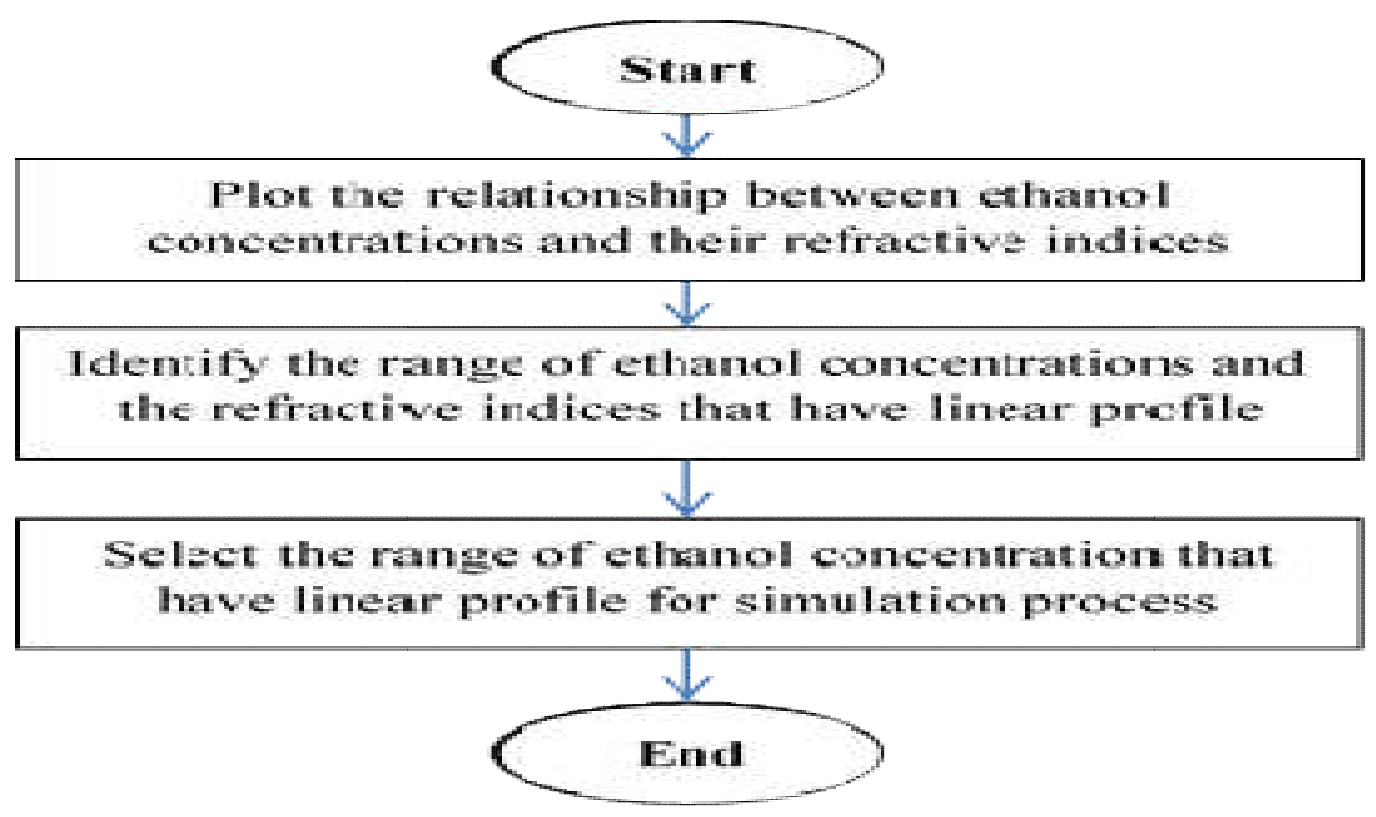

Fig.6. Research work in defining refractive index of ethanol at different concentration as simulation parameter

In this research study, the refractive index for different concentration of ethanol was totally referred to the data found in literature [12]. The reported refractive indices were measured with the Abbe refractometer at $25^{\circ} \mathrm{C}$. The referred data are tabulated in the Table 1. 
Table 1. Referred refractive index for different concentration of ethanol

\section{Referred Percentage of Ethanol-Water Mixture (wt\%)}

Referred Refractive Index (Measured at $25^{\circ} \mathrm{C}$ )

0

3.96

7.61

8.02

12.04

16.45

20.46

25.04

29.41

38.82

43.67

48.49

53.6

58.49

60.45

69.1

70.4

73.67

74.11

75.86

77.01

78.32

79.39

80.57

81.3

82.88

83.81

84.81

86.07

92.68

96.33
1.33276

1.33505

1.33720

1.33763

1.34068

1.34364

1.34678

1.34965

1.35188

1.35630

1.35795

1.35940

1.36075

1.36160

1.36185

1.36298

1.36304

1.36319

1.36321

1.36334

1.36341

1.36339

1.36331

1.36327

1.36325

1.36314

1.36307

1.36301

1.36292

1.36166

1.36083 
In order to find the relationship between refractive index and their concentration, data in Table 1 was plotted as in Fig. 7.

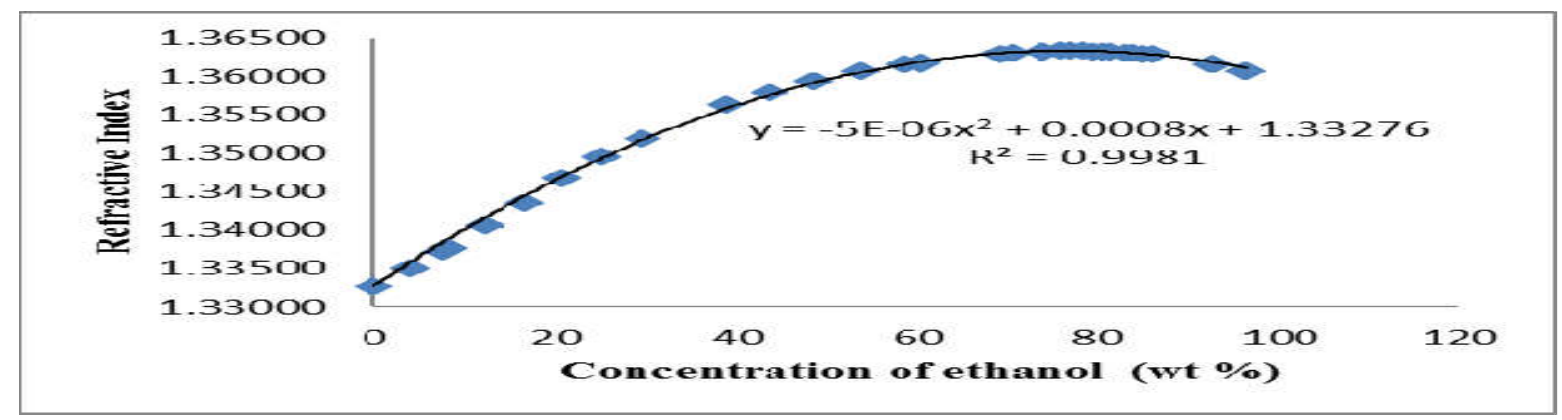

Fig.7. Relationship between referred refractive index and concentration of ethanol for 0-96.3

$$
\mathrm{wt} \%
$$

From Fig. 7, it was shown that, refractive index and concentration of ethanol have polynomial profile instead of the linear relationship. The data fits to $99.81 \%$ of polynomial power 2 . Nonlinear behaviour is observed in the refractive index with the increasing of the ethanol proportion in water. Since the concentration of ethanol will be prepared in volume percent (vol\%) in the experiment session, conversion unit from $\mathrm{wt} \%$ ethanol to vol\% must be done. Theoretically, for $1 \mathrm{ml}$ of water, the weight is $1 \mathrm{~g}$. While for $1 \mathrm{ml}$ of ethanol, the weight is $0.784 \mathrm{~g}$ which is slightly lower than water. The relationship between volume percent (vol\%) and weight ( $\mathrm{wt} \%$ ) of ethanol was correlated by using simple equation stated below. ethanol $(\operatorname{vol} \%)=[$ mass ethanol $/($ mass ethanol + mass water $)] \times 100 \%$ The amount of ethanol-water mixture in vol\% that are proportional to $\mathrm{wt} \%$ can be shown in Table 2. The approximated refractive index for ethanol-concentration in vol\% was computed based on the polynomial equation displayed on Fig. 7.

Table 2. Ethanol-water mixture in $\mathrm{Vol} \%$ and $\mathrm{Wt} \%$ and its approximated refractive index

\begin{tabular}{ccccccc}
\hline (vol\%) & Ethanol $(\mathbf{m l})$ & Water $(\mathbf{m l})$ & Ethanol $(\mathbf{g})$ & Water $(\mathbf{g})$ & $\mathbf{( w t \% )}$ & $\begin{array}{c}\text { Refractive } \\
\text { Index }\end{array}$ \\
\hline 0.00 & 0.00 & 100.0 & 0.00 & 100.0 & 0.0000 & 1.33276 \\
0.01 & 0.01 & 99.99 & 0.01 & 99.99 & 0.0079 & 1.33277 \\
0.05 & 0.05 & 99.95 & 0.04 & 99.95 & 0.0395 & 1.33279 \\
0.10 & 0.10 & 99.90 & 0.08 & 99.90 & 0.0790 & 1.33282 \\
0.50 & 0.50 & 99.50 & 0.40 & 99.50 & 0.3954 & 1.33308 \\
1.00 & 1.00 & 99.00 & 0.79 & 99.00 & 0.7916 & 1.33339 \\
2.50 & 2.50 & 97.50 & 1.98 & 97.50 & 1.9854 & 1.33433 \\
\hline
\end{tabular}




$\begin{array}{lcccccc}5.00 & 5.00 & 95.00 & 3.95 & 95.00 & 3.9919 & 1.33587 \\ 10.0 & 10.00 & 90.00 & 7.90 & 90.00 & 8.0694 & 1.33889 \\ 15.0 & 15.00 & 85.00 & 11.85 & 85.00 & 12.2354 & 1.34180 \\ 25.0 & 25.00 & 75.00 & 19.75 & 75.00 & 20.8443 & 1.34726 \\ 50.0 & 50.0 & 50.00 & 39.50 & 50.00 & 44.1340 & 1.35833 \\ 100 & 100.0 & 0.00 & 79.00 & 0.00 & 100.000 & 1.36276\end{array}$

Fig. 8 shows the plotting of approximated refractive indices of ethanol with respect to their vol \% based on polynomial equation.

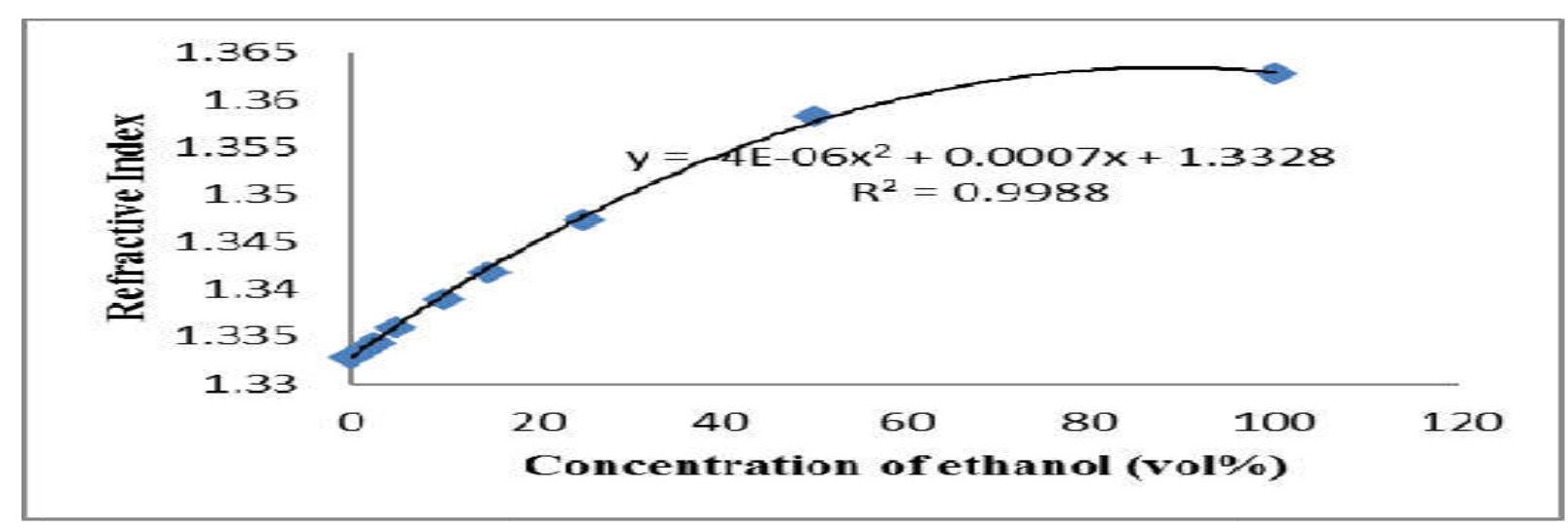

Fig.8. Relationship between approximated refractive index and 0-100vol\% ethanol concentration based on polynomial equation

The approximated refractive index also behaves as nonlinear profile as the concentration of ethanol increases from $0 \%-100 \%$. However, when the ethanol concentration was plotted from 0 vol\%-50 vol\% as in Fig. 9, it showed $99.44 \%$ of linearity profile.

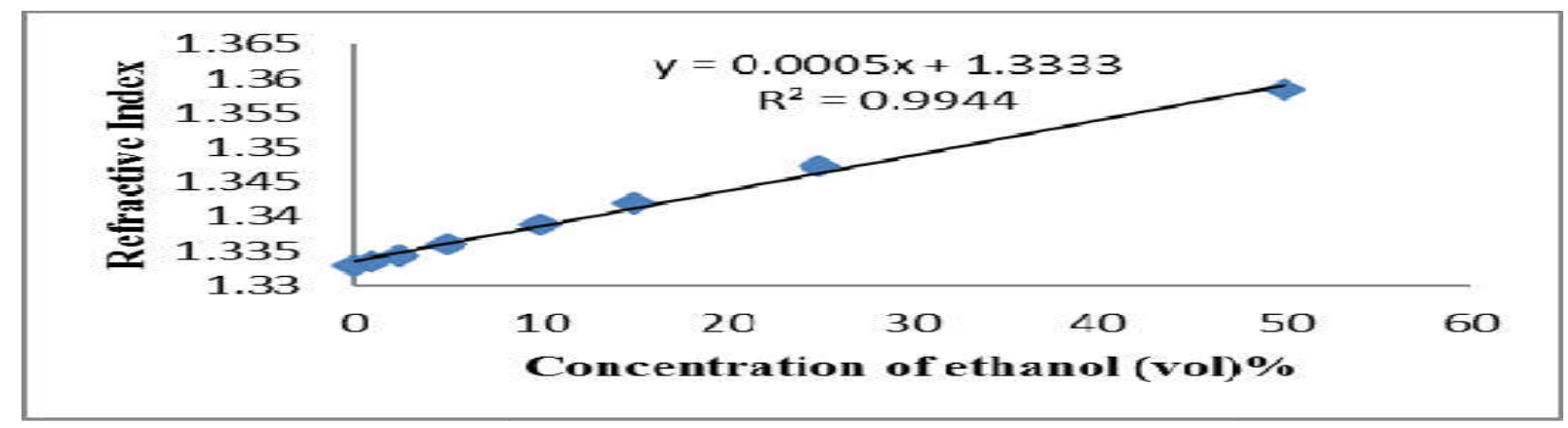

Fig.9. Relationship between approximated refractive index and $0-50 \mathrm{vol} \%$ ethanol concentration based on linear equation

In sensing, an optical sensor with a linear response is desirable compared to the nonlinear because it leads to a simple calibration of the sensors, a constant sensitivity and precision in measurement. Nonlinear response is not useful for practical purposes and real field applications. The feasibility of obtaining such a linear response has been briefly reported in 
[13-14]. Therefore, for that reasons, only ethanol concentration with $0 \%$ to $50 \%$ range will be considered in the simulation work.

\subsection{Optimizing Number of Analysis-Ray}

The suitable number of analysis-ray will determine the consistency or variation of the results. Optimization of analysis ray number is important in order to speed up the simulation time because once the results change minimally; an increase in the analysis-ray will only increase computation time but not the accuracy. In optimizing the number of analysis-ray, the simulation work was started with 5000 of analysis-ray and keep increased to 10,000, 25,000, $50,000,100,000$ and 150,000. The variation of output power with different number of analysis-ray are tabulated in Table 3.

Table 3. Variation of output power in different concentration of ethanol for different number of analysis-rays for $2.5 \mathrm{~cm}$ bending diameter

\begin{tabular}{ccccccc}
\hline Vol\% & & \multicolumn{5}{c}{ Output Power $\left(\mathbf{1 0}^{-4}\right)$ Watts } \\
& $\mathbf{5 0 0 0}$ & $\mathbf{1 0 0 0 0}$ & $\mathbf{2 5 0 0 0}$ & $\mathbf{5 0 0 0 0}$ & $\mathbf{1 0 0 0 0 0}$ & $\mathbf{1 5 0 0 0 0}$ \\
& Rays & Rays & Rays & Rays & Rays & Rays \\
\hline 0 & 5.868 & 5.738 & 5.7868 & 5.7818 & 5.7574 & 5.7464 \\
1 & 5.826 & 5.752 & 5.6876 & 5.7752 & 5.7526 & 5.7229 \\
2.5 & 5.648 & 5.724 & 5.7104 & 5.7216 & 5.7176 & 5.7075 \\
5 & 5.598 & 5.725 & 5.702 & 5.6834 & 5.6884 & 5.6914 \\
10 & 5.618 & 5.624 & 5.6416 & 5.612 & 5.5969 & 5.6196 \\
15 & 5.554 & 5.543 & 5.5672 & 5.5228 & 5.5278 & 5.5347 \\
25 & 5.356 & 5.350 & 5.4112 & 5.387 & 5.3909 & 5.3792 \\
50 & 5.134 & 5.012 & 5.021 & 5.0338 & 5.0454 & 5.0456
\end{tabular}

The variation of output power for different concentration of ethanol is plotted accordance to their number of analysis-ray as in Fig. 10. For each number of analysis-ray, the linearity of the output power and ethanol concentration was computed automatically by using Microsoft excel. In the figure, linearity of the data was denoted as $\mathrm{R}^{2}$ in each analysis rays. This linearity shows the consistency of the output power detected. 


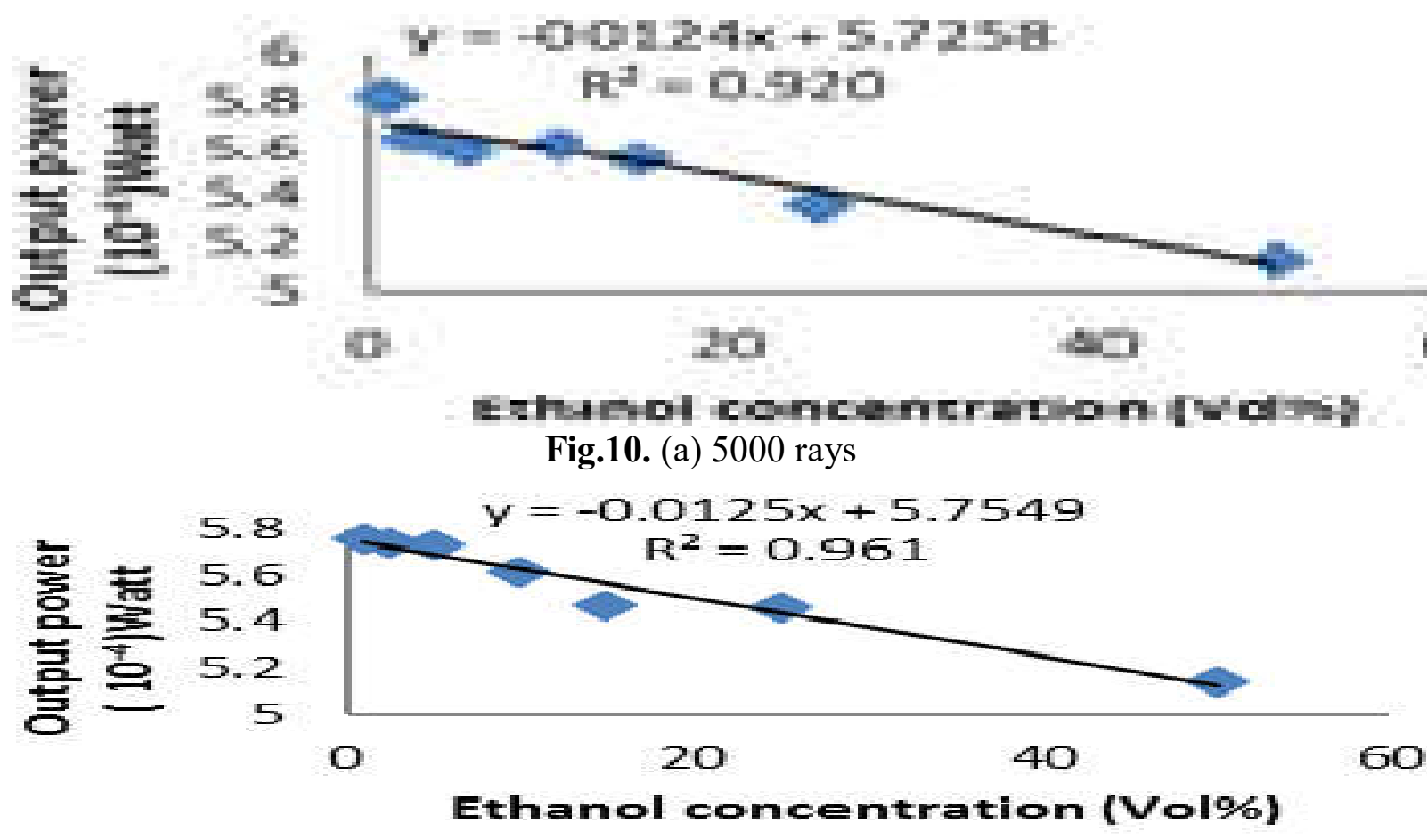

Fig.10. (b) 10000 rays

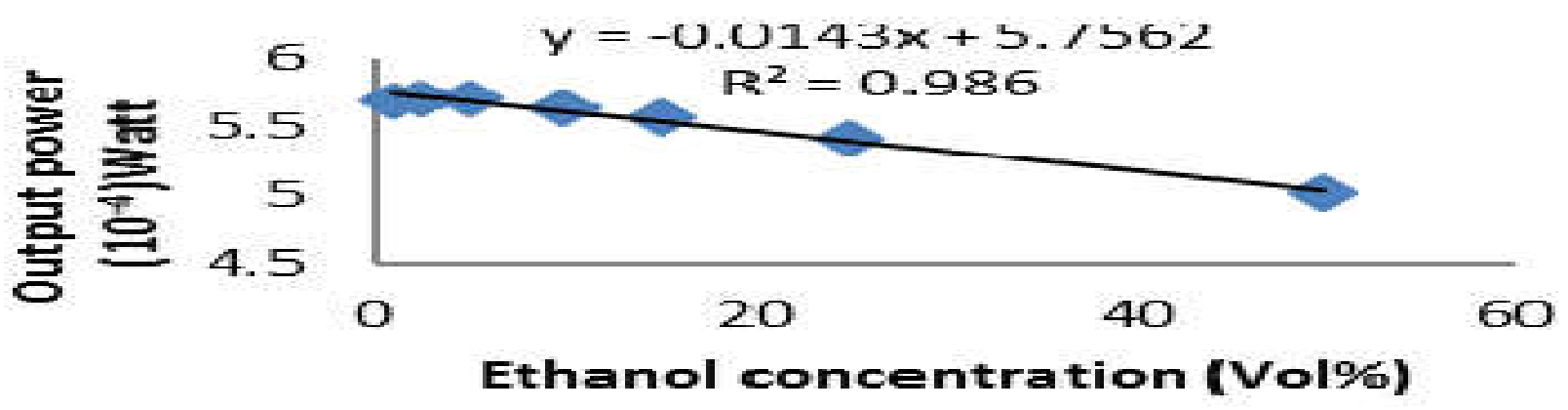

Fig.10. (c) 25000 rays

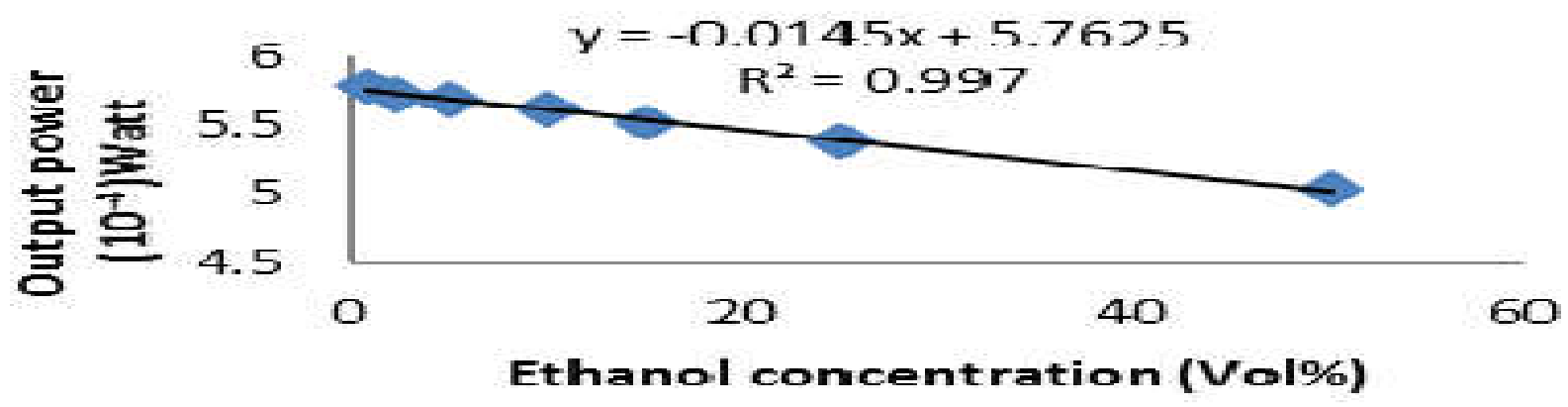

Fig.10. (d) 50000 rays

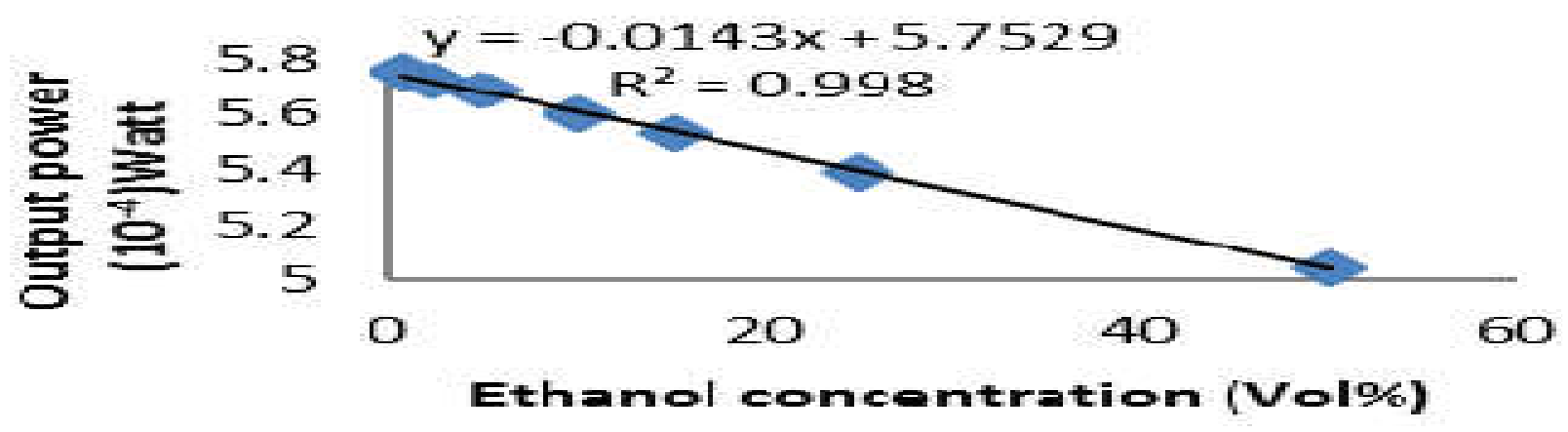




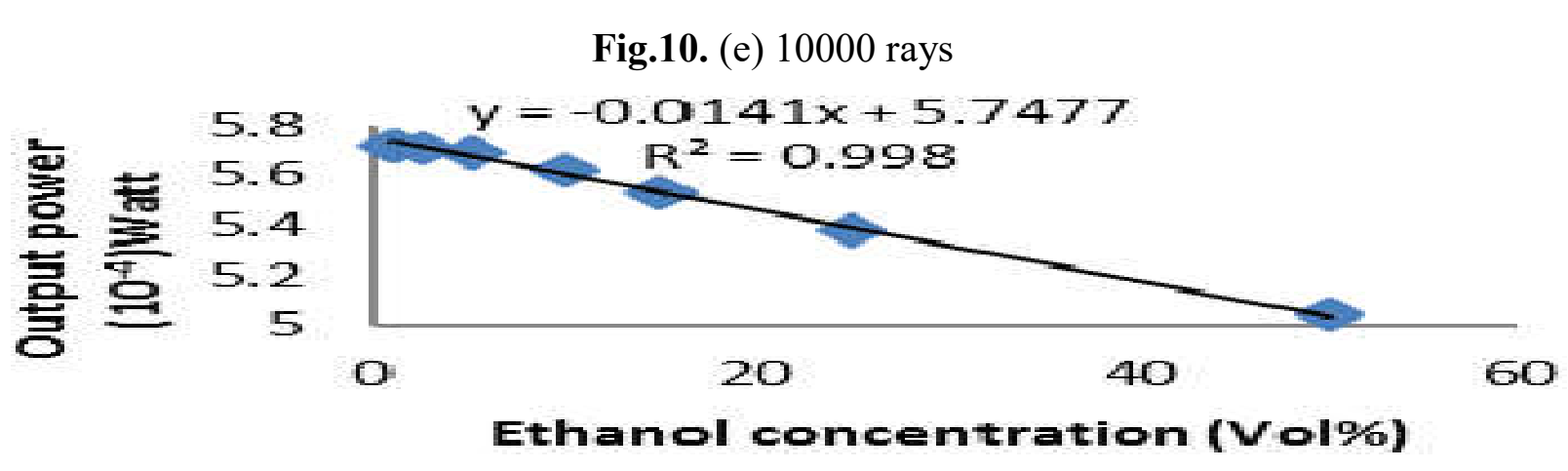

Fig.10. (f) 150000 rays

From Fig. 10, when the number of analysis ray-increased, the simulation time also increases but the variations of output power changed minimally. In the other words the linearity of the data is increased as the number of analysis ray increases. From Table 4, the linearity percentage of the data keep increased from 5000 to 50000 of analysis rays. However, the percentage remains unchanged to $99 \%$ until the number of analysis ray reached to 150,000 . This consistency response also can be seen graphically as in Fig. 11.

Table 4. Simulation time and linearity of the output power with respect to number of

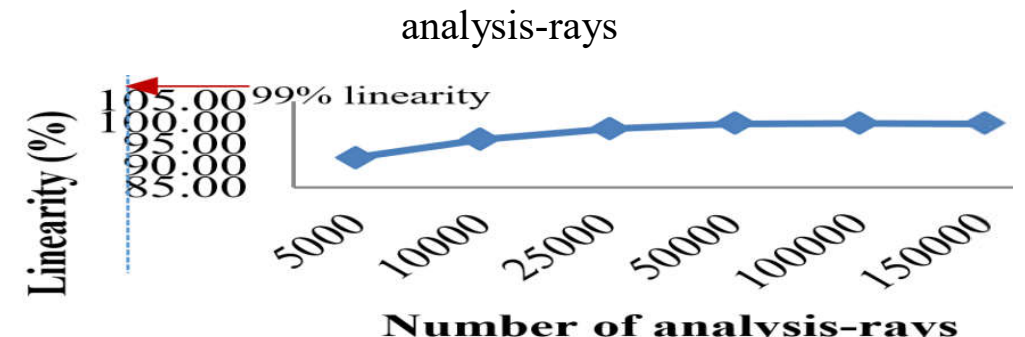

Fig.11. Relationship between linearity of the output power and the number of analysis-rays From Fig. 11 the linearity of the detected output power is increased as the number of analysis-ray increases. But, once the maximum linearity is reached, then it stabilized to the straight line. $99 \%$ of linearity was achieved when the number of analysis-ray was 50, 000, 100,000 and 150,000. However, 100,000 of analysis ray was chosen in the simulation process since the linearity of the data distribution is a bit higher than 50,000 rays.

\subsection{Simulation Work and Data Analysis of POF Sensor with Different Bending Diameters}

The steps in investigating the most sensitive POF bending diameter can be shown in Fig. 12 . The designed U-shaped POF sensor models with different bending diameter is imported one by one into Zemax software for simulation process. The detected output power in different concentration of ethanol for each bending diameter was plotted and the gradient of the plotted graph for each bending diameter was automatically calculated by using Microsoft excel. Bending diameter that has the highest gradient was defined as the most sensitive sensor. 


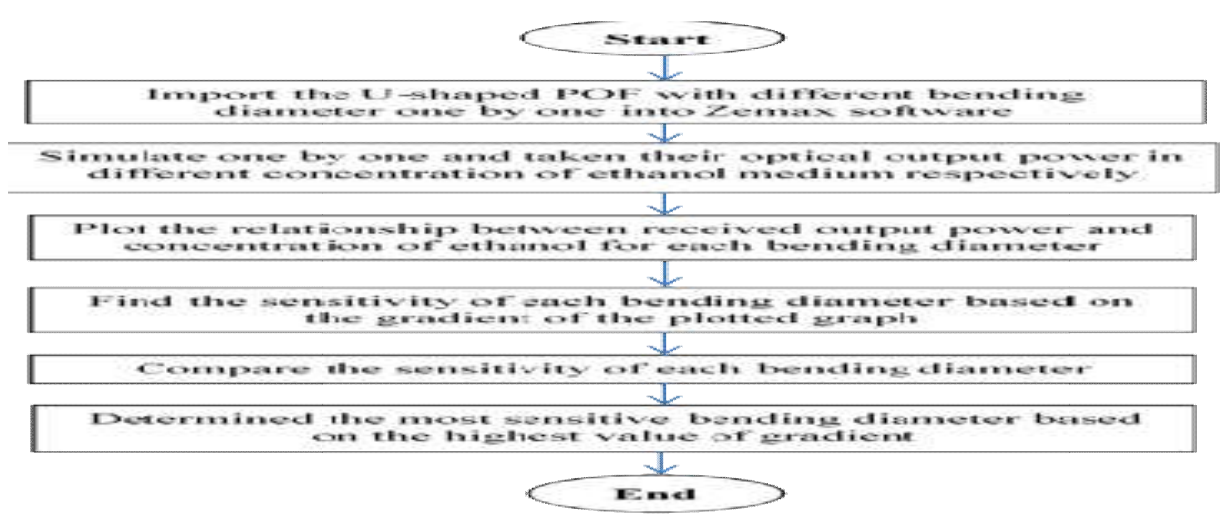

Fig.12. Process of investigating the most sensitive bending diameter

\section{RESULTS AND DISCUSSION}

In comparing the most sensitive bending diameter, the POF model was simulated without coated with cladding layer. Therefore, the thickness of the each POF model is $980 \mu \mathrm{m}$. The simulation results for different bending diameter are tabulated in the Table 4.

Table 4. Variation of output power for different bending diameter of POF sensor

\begin{tabular}{cccccc}
\hline $\begin{array}{c}\text { Ethanol Concentration } \\
\text { (Vol\%) }\end{array}$ & $\mathbf{2 . 0} \mathbf{~ c m}$ & $\mathbf{2 . 5} \mathbf{~ c m}$ & $\mathbf{3 . 0} \mathbf{~ c m}$ & $\mathbf{3 . 5} \mathbf{~ c m}$ & $\mathbf{4 . 0} \mathbf{~ c m}$ \\
\hline 0 & 5.6953 & 5.7604 & 5.9132 & 6.0284 & 6.1366 \\
1 & 5.6910 & 5.7475 & 5.9039 & 6.0268 & 6.1230 \\
2.5 & 5.6531 & 5.7434 & 5.8822 & 6.0032 & 6.0890 \\
5 & 5.6178 & 5.6997 & 5.8385 & 5.9723 & 6.0747 \\
10 & 5.5754 & 5.6049 & 5.7627 & 5.9037 & 5.9802 \\
15 & 5.4804 & 5.5381 & 5.6966 & 5.8126 & 5.8836 \\
25 & 5.3233 & 5.3991 & 5.5898 & 5.6911 & 5.7867 \\
50 & 5.0008 & 5.0548 & 5.2616 & 5.4090 & 5.5337 \\
\hline
\end{tabular}

The current finding in Table 5 is clearly supported by [10, 15-16]. In [15] reveal that for POF with bend radius greater than $1.5 \mathrm{~cm}$, their bending losses is not significance. On the other hand, in [10] also have found that for POF with the bending radius greater than $3 \mathrm{~cm}$, it does not give any appreciated loss. From their investigation, they found that, the power loss increases obviously as the bending radius is less than $3 \mathrm{~cm}$. in [16] also found that the POF with smaller curvature radius produced more bending losses. Results in Table 5 proves that as the bending radius getting smaller, less output power is captured since more lights was escaped from the fiber.

Table 5. Sensitivities for different bending diameter 


\begin{tabular}{cc}
\hline Bending Diameter (cm) & Sensitivity (Watt/Vol\%) \\
\hline 2.0 & 0.0141 \\
2.5 & 0.0143 \\
3.0 & 0.0130 \\
3.5 & 0.0128 \\
4.0 & 0.0121 \\
\hline
\end{tabular}

From Table 6, the sensitivity of the sensor is increased when the bending diameter was reduced. The results obtained is agreed with $[10,15-16]$. As the bending of the fiber increased, their sensitivity profile toward surrounding also increases. With a smaller radius, the fiber now allows some light to escape or re-enter the core depending upon on the amount of the curvature [17]. Therefore, fiber with a small bent will have higher sensitivity compared to the fiber with larger bending radii. When a fiber is bent, it radiates power to the surrounding medium. Extreme bending could lead the propagation rays to lose into the air if the cladding is thinned or stripped [18].

From Table 6, it was shown that POF with bending diameter of $2.0 \mathrm{~cm}$ and $2.5 \mathrm{~cm}$ has greater sensitivity compared to the POF with bending diameter $3.0 \mathrm{~cm}, 3.5 \mathrm{~cm}$ and $4.0 \mathrm{~cm}$. From the results, U-shaped with $2.5 \mathrm{~cm}$ bending diameter has demonstrated the most sensitive bending compared to the rest. Bending diameter with $2.0 \mathrm{~cm}$ might exceed the minimum bending diameter that leads to more power radiated to the surrounding. Thus, in overall the sensitivity will reduce.

Uncladded POF sensor with $2.5 \mathrm{~cm}$ bending is the most sensitive sensor. The effect of $20 \mu \mathrm{m}$ cladding layer on their sensitivity also was investigated. With the cladding, the total diameter of POF becomes $1000 \mu \mathrm{m}$. Table 7 shows the variation of output power for both conditions.

Table 6. Variation of output power for POF sensor without and with cladding layer

\begin{tabular}{ccc}
$\begin{array}{c}\text { Ethanol } \\
\text { Concentration } \\
(\text { Vol\%) }\end{array}$ & $\begin{array}{c}\text { Output Power for } \\
\text { POF without } \\
\text { Cladding (10 }\end{array}$ & $\begin{array}{c}\text { Output Power for } \\
\text { POF with }\end{array}$ \\
\hline 0 & 5.7574 & $\begin{array}{c}\text { Cladding }\left(\mathbf{1 0}^{-4} \text { Watts }\right) \\
1\end{array}$ \\
2.5 & 5.7526 & 5.7530 \\
5 & 5.7176 & 5.7574 \\
10 & 5.6884 & 5.7464 \\
& 5.5969 & 5.7062 \\
\end{tabular}




\begin{tabular}{lll}
\hline 15 & 5.5278 & 5.5193 \\
25 & 5.3909 & 5.4005 \\
50 & 5.0454 & 5.0653 \\
\hline
\end{tabular}

Sensitivities for both POF designs are shown in Fig. 13.

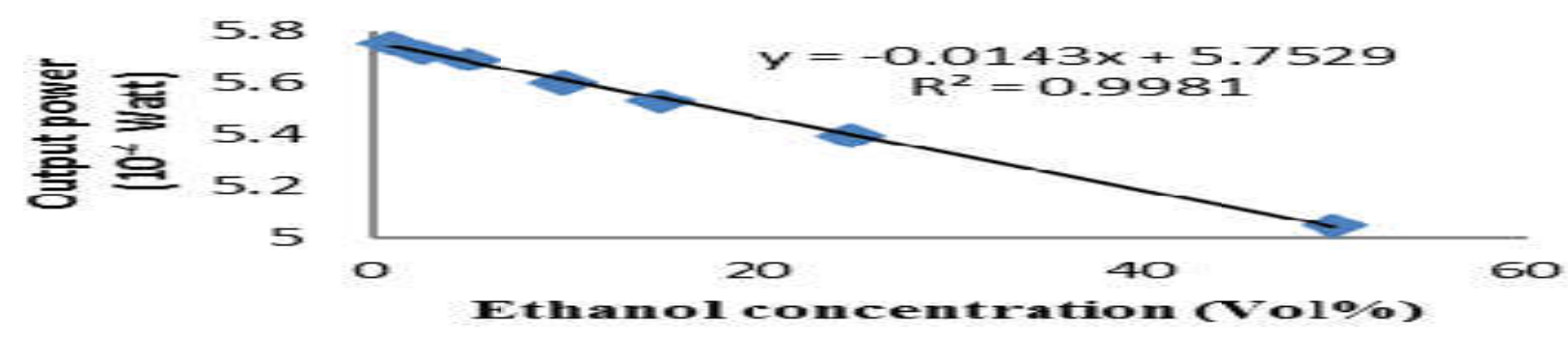

Fig.13. (a) POF without cladding

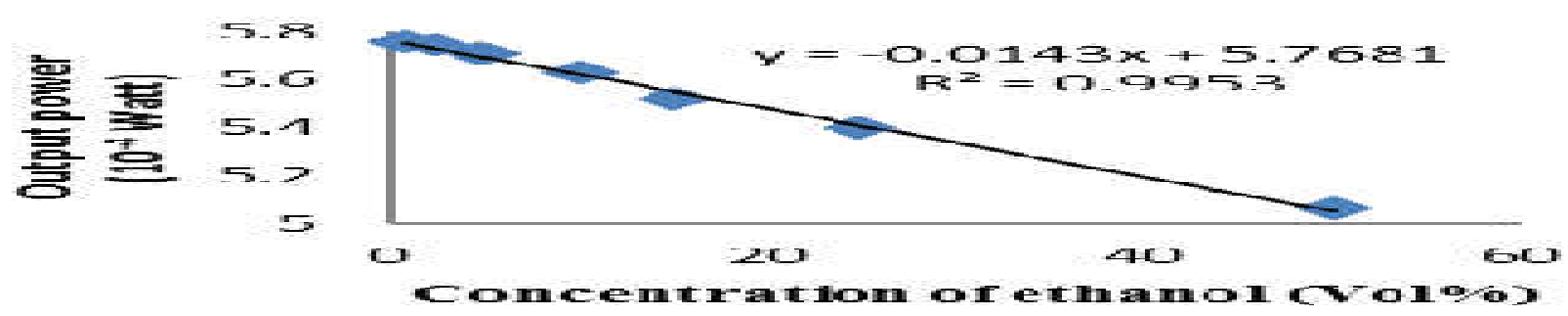

Fig.13. (b) POF with cladding

From Fig. 13, the sensitivity of the POF sensor for both conditions are $0.0143 \mathrm{watt} / \mathrm{vol} \%$. From the current finding, it can be concluded that cladding does not give any significant effect on the design and can be ignore in simulation.

\section{CONCLUSION}

The U-shaped POF sensing sensitivity was analyzed by considering an output power captured from the source diode profile. Based on the ray-tracing method, the optical bending loss for different bending diameter of U-shaped sensor configuration towards different refractive index were investigated. From the results obtained, it was clearly shows that U-shaped with $2.5 \mathrm{~cm}$ bending diameter has indicate the most sensitive gradient profile as compared to the 2.0, 3.0, 3.5 and $4.0 \mathrm{~cm}$ bending diameter. With $2.5 \mathrm{~cm}$ bending diameter, either with the presence of cladding layer or not, the sensitivity detected was $0.014 \times 10^{-4}$ Watts/Vol\%.

\section{ACKNOWLEDGEMENTS}

The authors would like to graciously acknowledge the Ministry of Higher Education and Universiti Teknologi MARA for supporting this research work through Grant No: FRGS/1/2016/TK04/UITM/03/5. 


\section{REFERENCES}

[1] Jiang S, Qiu H, Gao S, Chen P, Li Z, Yu K, Yue W, Yang C, Huo Y, Wang S. Evanescent wave absorption sensor based tapered plastic optical fiber coated with monolayer graphene for ethanol molecules detection. Chinese Journal of Chemistry, 2016, 34(10):1039-1047

[2] Gowri A, Sai V V. Development of LSPR based U-bent plastic optical fiber sensors. Sensors and Actuators B: Chemical, 2016, 230:536-543

[3] Fabian M, Lewis E, Newe T, Lochmann S, Mueller I. Investigation of ethanol and methanol water mixtures in the visible wavelength area using fibre-optic evanescent field absorption sensors based on a u-shaped, a coil-shaped and a meander-shaped probe. In IEEE Sensors Applications Symposium, 2008, pp. 79-84

[4] Saad H, Ali M T, Abd-Rahman M K. High sensitivity optical POF sensor for detecting low ethanol concentration in water. Advanced Materials Research, 2015, 1107:693-698

[5] Jones S L, Murtaza G, Senior J M, Haigh N. Single-mode optical fiber microbend loss modeling using the finite difference beam propagation method. Optical Fiber Technology, 1998, 4(4):471-479

[6] Lorenser D, Yang X, Sampson D D. Accurate modeling and design of graded-index fiber probes for optical coherence tomography using the beam propagation method. IEEE Photonics Journal, 2013, 5(2):1-16

[7] Yang H Z, Qiao X G, Ali M M, Islam M R, Lim K S. Optimized tapered optical fiber for ethanol $\left(\mathrm{C}_{2} \mathrm{H}_{5} \mathrm{OH}\right)$ concentration sensing. Journal of Lightwave Technology, 2014, 32(9):1777-1783

[8] Jiménez F, Arrue J, Aldabaldetreku G, Zubia J. Numerical simulation of light propagation in plastic optical fibres of arbitrary 3D geometry. WSEAS Transactions on. Mathematics, 2004, 3:824-829

[9] Lin X, Ren L, Qu E, Liang J, Ju H. Theoretical and experimental study on nonintrusive light injection via cladding in plastic optical fibers. Journal of Lightwave Technology, 2013, 31(3):359-365

[10] Kuang J H, Chen P C, Chen Y C. Plastic optical fiber displacement sensor based on dual cycling bending. Sensors, 2010, 10(11):10198-10210

[11] ZEMAX LLC. ZEMAX optical design program user's guide. 2011, https://neurophysics.ucsd.edu/Manuals/Zemax/ZemaxManual.pdf 
[12] Nowakowska J. The refractive indices of ethyl alcohol and water mixtures. Master thesis, Illinois: Loyola University Chicago, 1939

[13] Lin J, Liu D. An optical pH sensor with a linear response over a broad range. Analytica Chimica Acta, 2000, 408(1):49-55

[14] Aneesh R, Khijwania S K. An optical fiber humidity sensor with linear response. In International Conference on Optics and Photonics, 2009, pp. 1-4

[15] Durana G, Zubia J, Arrue J, Aldabaldetreku G, Mateo J. Dependence of bending losses on cladding thickness in plastic optical fibers. Applied Optics, 2003, 42(6):997-1002

[16] Remouche M, Georges F, Meyrueis P. Flexible optical waveguide bent loss attenuation effects analysis and modeling application to an intrinsic optical fiber temperature sensor. Optics and Photonics Journal, 2012, 2(1):1-7

[17] Brush U J. Design and validation of an intensity-based POF bend sensor applications in measuring three-dimensional trunk motion. Master thesis, Columbus: Ohio State University, 2010

[18] Supian L S, Ab-Rahman M S, Arsad N, Ramza H. Study of macro-bending of polymer fiber in multimode POF couplers development by lapping technique. International Journal of New Computer Architectures and their Applications. 2014, 4(1):39-47

\section{How to cite this article:}

Saad H, Rahman MKA, YusoffMHM, Kassim NSM, Yassin I.. Simulation of u-shaped plastic optical fiber ethanol sensor. J. Fundam. Appl. Sci., 2017, 9(4S), 401-416. 